\title{
Effective thermal conductivity of real two-phase systems using resistor model with ellipsoidal inclusions
}

\author{
JAGJIWANRAM* and RAMVIR SINGH \\ Department of Physics, University of Rajasthan, Jaipur 302 004, India
}

MS received 9 January 2004

\begin{abstract}
A theoretical model has been developed for real two-phase system assuming linear flow of heat flux lines having ellipsoidal particles arranged in a three-dimensional cubic array. The arrangement has been divided into unit cells, each of which contains an ellipsoid. The resistor model has been applied to determine the effective thermal conductivity (ETC) of the unit cell. To take account of random packing of the phases, non-uniform shape of the particles and non-linear flow of heat flux lines in real systems, incorporating an empirical correction factor in place of physical porosity modifies an expression for ETC. An effort is made to correlate it in terms of the ratio of thermal conductivities of the constituents and the physical porosity. Theoretical expression so obtained has been tested on a large number of samples cited in the literature and found that the values predicted are quite close to the experimental results. Comparison of our model with different models cited in the literature has also been made.
\end{abstract}

Keywords. Real two-phase systems; effective thermal conductivity; correction term.

\section{Introduction}

The theoretical modelling for two-phase dissimilar systems of industrial importance is a challenging task for engineers and physicists, and of major interest to soil scientists and geologists. It is required because of increasing use of porous substances as insulating envelops in solar ponds, non-conventional refrigerators, air conditioners and high temperature furnaces. The study of thermal parameters of these two-phase systems is also valuable for the explosive industry, the ceramics industry, nuclear reactors and in missile technology. High fluid porosity metal foams have long been used in design of aircraft wing structure in the aerospace industry, catalytic surfaces for chemical reactions, core structure for high strength panels, and containment matrix and burn rate heat exchanger for solid propellants. The ETC depends on various factors such as thermal conductivity, porosity, size of the particles and packing of the constituent phases. Accounting for all these factors in order to predict ETC is a complex affair. In the literature one finds several efforts (Babanov 1957; Brailsford and Major 1964; Pande et al 1984; Hadley 1986; Oshima and Watari 1989; Verma 1991) in which the situation has been simplified by assuming that the particles are of specific shape and arranged in particular geometries within the continuous phase.

The value of thermal conductivity in the solid-fluid composite is required in the numerical modelling of forced

\footnotetext{
*Author for correspondence
}

convection through porous media (Poulikakos et al 1987). Hunt and Tien (1988) used an empirical stagnant conduction model developed by Tien and Vafai (1979) to define the effective thermal conductivity in the volume averaged homogeneous energy equation. Antohe et al (1996) also emphasized the use of an empirical phase symmetry conduction that was developed by Hsu et al (1994) to create a numerical model for the simulation of cooling micro heat exchangers. The origins of the phase-symmetry conduction model by Hsu et al (1994) are based upon the original work done by Zehner and Schlunder (1970) on packed beds of spheres. In a configuration with a low solid volume fraction and order of magnitude differences between the thermal conductivities of the two phases, the key in estimating the effective thermal conductivity is an accurate description of the geometry of the solid medium (Kaviany 1995). Zehner and Schlunder (1970) used this technique successfully for a packed bed of spheres. A recent advancement in the estimation of the effective thermal conductivity specifically for metallic foams saturated with a fluid utilizing a geometrical estimate was developed by Calmidi and Mahajan (1999) and Boomsma and Poulikakos (2001). For high porosity metal foams Calmidi and Mahajan (1999) presented a one-dimensional heat conduction model considering the porous medium to be formed of a two-dimensional array of hexagonal cells. Whereas Boomsma and Poulikakos (2001) proposed a three-dimensional model using metal foam structure in the form of tetrakaidecahedral cells with cubic nodes at the intersection of two nodes. Both the models involved a geometric parameter that was evaluated using the 
experimental data. Recently, Bhattacharya et al (2002) extended the analysis of Calmidi and Mahajan (1999) with a circular intersection, which results in a six-fold rotational symmetry.

In the present paper we have tried to fill the space arrangement of cells of equal size with the minimal surface energy and a theoretical model has been proposed to predict ETC of two-phase system with ellipsoidal inclusions. The arrangement has been divided into unit cells each of which contains an ellipsoid. The resistor model has been applied to determine the effective thermal conductivity (ETC) of the unit cell. However, in real systems, the packing and the shape of the particles are random. In order to incorporate varying individual geometries and non-linear flow of heat flux lines generated by the difference in thermal conductivities of constituent phases, a correction term in place of the physical porosity has been introduced. In the literature similar attempts have been made (Kampf and Karsten 1970; Koh and Fortini 1973; Peddicord 1976; Misra et al 1994; Singh et al 1995; Singh K J et al 1998), but for limited ETC ratios. Expressions for the porosity correction term have been obtained empirically by simulating experimental data reported in the literature. The present approach is simple and provides wider applicability to ellipsoidal model and enhances its ability to predict correctly the ETC of real two-phase system and systems having high ratios of thermal conductivities of their constituent phases.

\section{Theory}

We assume the following while analysing the problem: (i) the contact resistance between the solid and fluid phase is negligible, (ii) the mixture is homogeneous throughout and no transfer of heat occurs by way of convection or radiation and (iii) the heat flows along the $x$-axis and the flux lines remain parallel during the heat flow.

Let the grains of the solid phase be ellipsoidal having principal axes $2 a, 2 c$ and $2 a(a<c)$. Let these grains be located at the corners of a simple cube of side $2 b$ each. Their distribution in two dimensions is shown in figure 1(a). The geometry of a unit cell is shown in figure 1(b).

Let the origin of coordinate axes be located at the centre of the ellipsoid. The unit cell can be divided into thin slices by planes perpendicular to the $x$-axis. Consider one such slice bounded by two planes at distances $x$ and $x+\mathrm{d} x$. The section shown in figure $1(\mathrm{c})$ is subdivided into four quadrants. One such section is shown in figure 1(d). This section is further divided by planes perpendicular to the $z$-axis. This results in the section of rectangular bars. One such bar is shown in figure 1(e). Let the length of the bar be $b$. Its cross-sectional area will be $\mathrm{d} x \mathrm{~d} z$. The shaded portion of the element in figure $1(\mathrm{~d})$ represents the solid phase and the non-shaded portion represents the fluid phase. This is supposed that the heat flux is incident normally on the cubic cell.
The volume fraction of the solid phase will be

$$
(y \mathrm{~d} x \mathrm{~d} z) /(b \mathrm{~d} x \mathrm{~d} z)=y / b .
$$

Similarly, the volume fraction of the fluid phase will be

$$
\begin{gathered}
\{(b-y) \mathrm{d} x \mathrm{~d} z\} /(b \mathrm{~d} x \mathrm{~d} z), \\
=(1-y / b) .
\end{gathered}
$$

The terms $(y / b)$ and $(1-y / b)$ are equivalent to the onedimensional porosity as used by Cheng and Vachon (1969). Considering various components as resistors one can take a combination of such resistors to predict ETC. As these elements form parallel resistors with respect to the direction of heat flow, therefore, using the resistor model the thermal conductivity of the bar will be

$$
\lambda^{\prime}=\lambda_{1}(y / b)+\lambda_{2}(1-y / b)
$$

where $\lambda_{1}$ and $\lambda_{2}$ are the thermal conductivities of solid and fluid phases, respectively. With reference to figure 1(d), the thermal conductivity of the section will be

$$
\begin{aligned}
& \lambda^{\prime \prime}=\frac{(a b \mathrm{~d} x)}{b^{2} \mathrm{~d} x} \lambda_{\mathrm{av}}^{\prime}+\frac{(b-a) b \mathrm{~d} x}{b^{2} \mathrm{~d} x} \lambda_{2}, \\
& \lambda^{\prime \prime}=(a / b) \lambda_{\mathrm{av}}^{\prime}+(1-a / b) \lambda_{2},
\end{aligned}
$$

where

$$
\lambda_{\mathrm{av}}^{\prime}=(1 / a) \int_{0}^{a} \lambda^{\prime} \mathrm{d} z .
$$

By combining (4) and (5), we get the following result

$$
\lambda^{\prime \prime}=(1 / b) \int_{0}^{a} \lambda^{\prime} \mathrm{d} z+(1-a / b) \lambda_{2}
$$

With reference to figure $1(\mathrm{~d})$, we have

Volume fraction of portions numbered 1

$$
=(a b \mathrm{~d} x) /\left(b^{2} \mathrm{~d} x\right)=(a / b)
$$

Volume fraction of portions numbered 2

$$
=\left\{\left(b^{2}-b a\right) \mathrm{d} x\right\} /\left(b^{2} \mathrm{~d} x\right)=(1-a / b) .
$$

These elements form equivalent series resistors perpendicular to the direction of heat flow, therefore, the effective thermal conductivity $\left(\lambda_{\mathrm{e}}\right)$ of the unit cell can be written as

$$
\frac{1}{\lambda_{\mathrm{e}}}=\frac{(a / b)}{\lambda_{\mathrm{av}}^{\prime \prime}}+\frac{(1-a / b)}{\lambda_{2}} .
$$

Since $\lambda^{\prime \prime}$ varies as $x$ changes from 0 to $a$, therefore, on averaging

$$
\lambda_{\mathrm{av}}^{\prime \prime}=(1 / a) \int_{0}^{a} \lambda^{\prime \prime} \mathrm{d} x
$$


By combining (6) and (10), we get the following result

$$
\lambda_{\mathrm{av}}^{\prime \prime}=(1 / a) \int_{0}^{a}\left[(1 / b) \int_{0}^{a} \lambda^{\prime} \mathrm{d} z+(1-a / b) \lambda_{2}\right] \mathrm{d} x
$$

By combining (3) and (11), we get the following result

$$
\begin{aligned}
\lambda_{\mathrm{av}}^{\prime \prime}= & (1 / a) \int_{0}^{a}\left[( 1 / b ) \int _ { 0 } ^ { a } \left\{\lambda_{1}(y / b)+\right.\right. \\
& \left.\left.\lambda_{2}(1-y / b)\right\} \mathrm{d} z+(1-a / b) \lambda_{2}\right] \mathrm{d} x,
\end{aligned}
$$

Therefore,

$$
\lambda_{\mathrm{av}}^{\prime \prime}=\left\{\left(\lambda_{1}-\lambda_{2}\right) /\left(a b^{2}\right)\right\} \int_{0}^{a} \int_{0}^{a} y \mathrm{~d} x \mathrm{~d} z+\lambda_{2} .
$$

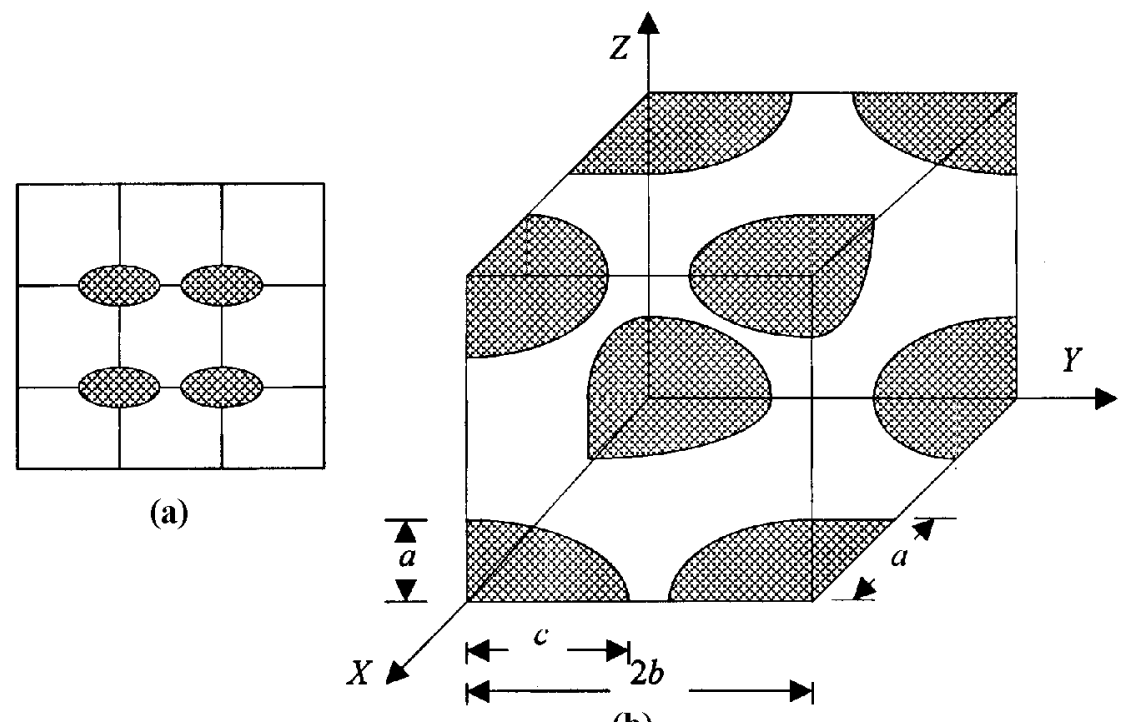

(b)

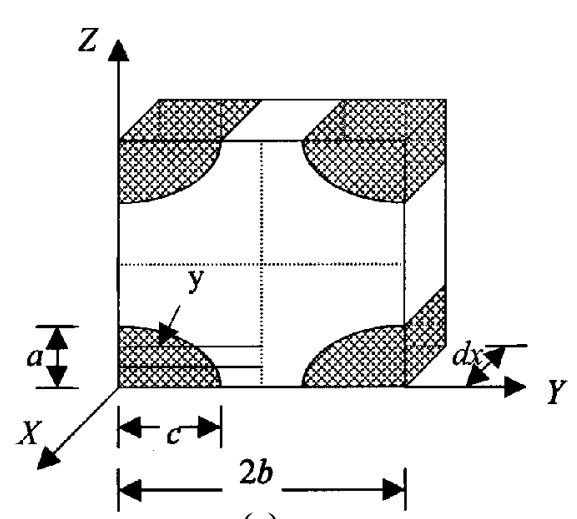

(c)

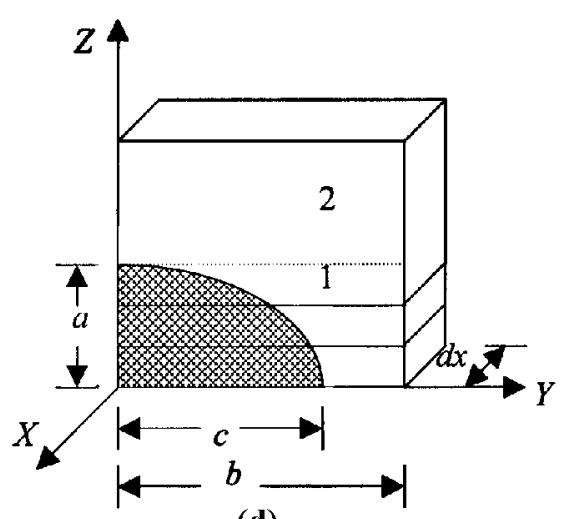

(d)

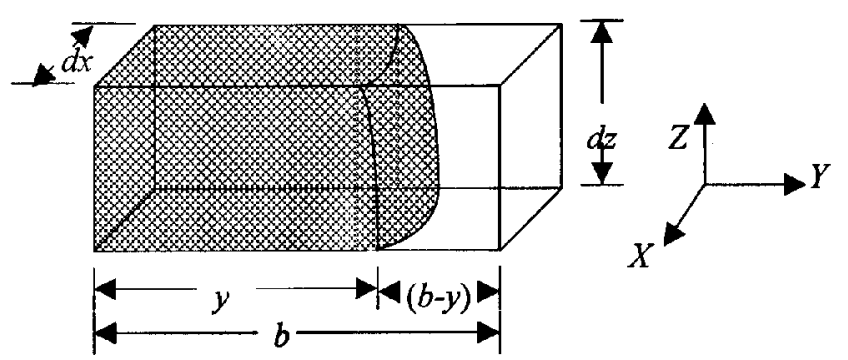

(e)

Figure 1. The resistor model for two-phase systems with ellipsoidal particles: (a) particles distribution in two dimensions, (b) geometry of a unit cell, (c) one section of unit cell, (d) one part of the section and (e) rectangular bar. 
For an ellipsoidal particle we have

$$
\left(x^{2} / a^{2}\right)+\left(y^{2} / c^{2}\right)+\left(z^{2} / a^{2}\right)=1,
$$

Therefore,

$$
y=c \sqrt{ }\left\{1-\left(x^{2} / a^{2}\right)-\left(z^{2} / a^{2}\right)\right\} .
$$

By combining (12) and (13), we get the following result

$$
\begin{aligned}
\lambda_{\mathrm{av}}^{\prime \prime}= & \left\{\left(\lambda_{1}-\lambda_{2}\right) /\left(a b^{2}\right)\right\} \int_{0}^{a} \int_{0}^{a} c \\
& \sqrt{ }\left\{1-\left(x^{2} / a^{2}\right)-\left(z^{2} / a^{2}\right)\right\} \mathrm{d} x \mathrm{~d} z+\lambda_{2}, \\
= & \left\{\left(\lambda_{1}-\lambda_{2}\right) /\left(a b^{2}\right)\right\}\left\{\left(\pi a^{2} c\right) / 6\right\}+\lambda_{2},
\end{aligned}
$$

Therefore,

$$
\lambda_{\mathrm{av}}^{\prime \prime}=\left\{\left(\lambda_{1}-\lambda_{2}\right) \pi a c\right\} /\left(6 b^{2}\right)+\lambda_{2} .
$$

By combining (9) and (14), we get the following result

$$
\frac{1}{\lambda_{\mathrm{e}}}=\frac{(a / b)}{\left\{\left(\lambda_{1}-\lambda_{2}\right) \pi a c\right\} /\left(6 b^{2}\right)+\lambda_{2}}+\frac{(1-a / b)}{\lambda_{2}},
$$

Therefore,

$$
\lambda_{\mathrm{e}}=\frac{\lambda_{2}\left[\left(\lambda_{1}-\lambda_{2}\right)\left\{(\pi a c) /\left(6 b^{2}\right)\right\}+\lambda_{2}\right]}{\left[(1-a / b)\left(\lambda_{1}-\lambda_{2}\right)\left\{(\pi a c) /\left(6 b^{2}\right)\right\}\right]+\lambda_{2}} .
$$

The unit cell contains one ellipsoid that lies inside. Therefore, fractional volume of the solid phase will be

$$
\phi_{1}=\frac{\left\{(4 / 3)\left(\pi a^{2} c\right)\right\}}{8 b^{3}}
$$

Therefore,

$$
\phi_{1}=\left\{\left(\pi a^{2} c\right) /\left(6 b^{3}\right)\right\} .
$$

Putting the limiting condition into (16), if $c=b$, we get the following result

$$
\phi_{1}=(\pi / 6)\left(a^{2} / b^{2}\right)
$$

Therefore,

$$
(a / b)=\{\sqrt{ }(6 / \pi)\} \phi_{1}{ }^{1 / 2} .
$$

In this configuration the two ellipsoids are in contact with negligible contact resistance.

By combining (15) and (17), we get the following result

$$
\lambda_{\mathrm{e}}=\frac{\lambda_{2}\left[\left(\lambda_{1}-\lambda_{2}\right)\{\sqrt{ }(\pi / 6)\} \phi_{1}{ }^{1 / 2}+\lambda_{2}\right]}{\left[\left(1-\{\sqrt{ }(6 / \pi)\} \phi_{1}^{1 / 2}\right)\left(\lambda_{1}-\lambda_{2}\right)\{\sqrt{ }(\pi / 6)\} \phi_{1}^{1 / 2}\right]+\lambda_{2}}
$$

For cubic packing of ellipsoidal inclusions the maximum value of the packing fraction will be $<0.52$ (because $a<b$ ). So (18) is valid for $0<\phi_{1}<0.52$ which is a low and medium dispersion case. In the limiting case, it can be seen that, when $\phi_{1}$ tends to $0, \lambda_{\mathrm{e}}$ approaches $\lambda_{2}$ and when $\phi_{1}$ tends to $0 \cdot 52, \lambda_{\mathrm{e}}$ leads to arithmetic mean of the phases. Noting that (18) is based on rigid geometry and it does not represent the true state of affairs of a real two-phase system. The ETC depends upon various characteristics of the system. The most prominent amongst them being the volume fraction and thermal conductivity of the constituent phases.

Thus, for practical utilization, we have to modify (18) by incorporating some correction term. Tareev (1975) has shown that, during the flow of electric flux from one dielectric to another dielectric medium, the deviation of flux lines in any medium depends upon the ratio of the dielectric constants of the two media. By the analogy we can have the concentration of thermal flux altered from its previous value as it passes through another medium and that the amount is a function of the thermal conductivities of the constituent phases. Such a deviation causes a zigzag path of flux lines in the bulk and also alters the density of flux lines in the constituent phases. The concentration of flux lines is greater in the phase of higher conductivity than it is in the phase of lower conductivity. If the flow of flux lines were linear then this porosity function would have been numerically equal to the physical porosity of the sample. In cases where curvature in the flow lines occur, the porosity function will not be equal to the physical porosity of the sample but it should be a function of the ratio of the thermal conductivities of the constituent phases as well as of the physical porosity of the sample. Considering random packing of phases, non-uniform shape of particles and the flow of heat flux lines not restricted to be parallel we here replace physical volume fraction of solid phase by porosity correction term $F . F$ in general should be a function of the physical volume fraction of the solid phase and the ratio of the thermal conductivities of the constituent phases. Therefore, (18) may be written as

$$
\lambda_{\mathrm{e}}=\frac{\lambda_{2}\left[\left(\lambda_{1}-\lambda_{2}\right)\{\sqrt{ }(\pi / 6)\} F^{1 / 2}+\lambda_{2}\right]}{\left[\left(1-\{\sqrt{ }(6 / \pi)\} F^{1 / 2}\right)\left(\lambda_{1}-\lambda_{2}\right)\{\sqrt{ }(\pi / 6)\} F^{1 / 2}\right]+\lambda_{2}}
$$

Rearranging (19) we get

$$
A F+B F^{1 / 2}+C=0
$$

where

$$
A=\left[\lambda e\left(\lambda_{1}-\lambda_{2}\right)\right], B=\left[\{\sqrt{ }(\pi / 6)\}\left(\lambda_{1}-\lambda_{2}\right)\left(\lambda_{2}-\lambda \mathrm{e}\right)\right]
$$

and $C=\lambda_{2}\left(\lambda_{2}-\lambda e\right)$

\section{Results and discussion}

Tables 1-2 cite experimental results of ETC and other data reported in literature. Without any correction term, (18) exhibits large deviations from the experimental results. This prompted the introduction of a correction in porosity. 
The correction term introduced for each sample has been computed using (20) and plotted with $\phi_{1}{ }^{1 / 2} \exp \left(\lambda_{2} / \lambda_{1}\right)$. Such plots of $\phi_{1}{ }^{1 / 2} \exp \left(\lambda_{2} / \lambda_{1}\right)$ versus $F^{1 / 2}$ are shown in figures $2-4$. It is observed from the figures that $F^{1 / 2}$ increases roughly linearly with increasing $\phi_{1}^{1 / 2} \exp \left(\lambda_{2} / \lambda_{1}\right)$. We have used the curve fitting technique and found that the expression

$$
F^{1 / 2}=C_{1} \phi_{1}{ }^{1 / 2} \exp \left(\lambda_{2} / \lambda_{1}\right)+C_{2},
$$

Table 1. Comparison of ETC values for two-phase systems using ellipsoidal particles (19). The thermal conductivity is in $\mathrm{W} \mathrm{m}^{-1} \mathrm{~K}^{-1}$.

\begin{tabular}{|c|c|c|c|c|c|c|c|}
\hline $\begin{array}{l}\text { Sl. } \\
\text { No. }\end{array}$ & Type of the sample & $\phi_{1}$ & $\lambda_{1}$ & $\lambda_{2}$ & $\lambda \mathrm{e}(\operatorname{expt})$ & $\begin{array}{c}\lambda \mathrm{e} \text { (theo.) } \\
\text { by (19) }\end{array}$ & $\begin{array}{c}\% \\
\text { Error }\end{array}$ \\
\hline 1 & $\mathrm{Cu} /$ solder $^{\mathrm{a}}$ & $0 \cdot 0124$ & $398 \cdot 0$ & $78 \cdot 1$ & $79 \cdot 8$ & $80 \cdot 918$ & 1.4 \\
\hline 2 & $\mathrm{Cu} /$ solder $^{\mathrm{a}}$ & $0 \cdot 0136$ & $398 \cdot 0$ & $78 \cdot 1$ & $80 \cdot 0$ & $81 \cdot 149$ & 1.4 \\
\hline 3 & $\mathrm{Cu} /$ solder $^{\mathrm{a}}$ & 0.0507 & $398 \cdot 0$ & $78 \cdot 1$ & $85 \cdot 2$ & $87 \cdot 591$ & $2 \cdot 8$ \\
\hline 4 & $\mathrm{Cu} /$ solder $^{\mathrm{a}}$ & 0.0996 & $398 \cdot 0$ & $78 \cdot 1$ & $92 \cdot 4$ & $95 \cdot 471$ & $3 \cdot 3$ \\
\hline 5 & $\mathrm{Cu} /$ solder $^{\mathrm{a}}$ & 0.0195 & $398 \cdot 0$ & $78 \cdot 1$ & $80 \cdot 8$ & $82 \cdot 249$ & 1.8 \\
\hline 6 & $\mathrm{Cu} /$ solder $^{\mathrm{a}}$ & 0.0263 & $398 \cdot 0$ & $78 \cdot 1$ & $81 \cdot 7$ & 83.466 & $2 \cdot 1$ \\
\hline 7 & $\mathrm{Cu} /$ solder $^{\mathrm{a}}$ & 0.0286 & $398 \cdot 0$ & $78 \cdot 1$ & $82 \cdot 0$ & $83 \cdot 869$ & $2 \cdot 3$ \\
\hline 8 & $\mathrm{Cu} /$ solder $^{\mathrm{a}}$ & $0 \cdot 1029$ & $398 \cdot 0$ & $78 \cdot 1$ & $92 \cdot 7$ & 95.999 & $3 \cdot 5$ \\
\hline 9 & $\mathrm{Cu} /$ solder $^{\mathrm{a}}$ & $0 \cdot 2377$ & $398 \cdot 0$ & $78 \cdot 1$ & $115 \cdot 4$ & $118 \cdot 878$ & $3 \cdot 0$ \\
\hline 10 & $\mathrm{Cu} /$ solder $^{\mathrm{a}}$ & 0.0848 & $398 \cdot 0$ & $78 \cdot 1$ & $90 \cdot 2$ & $93 \cdot 101$ & $3 \cdot 2$ \\
\hline 11 & $\mathrm{Cu} /$ solder $^{\mathrm{a}}$ & $0 \cdot 1586$ & $398 \cdot 0$ & $78 \cdot 1$ & $102 \cdot 0$ & $105 \cdot 068$ & $3 \cdot 0$ \\
\hline 12 & $\mathrm{Cu} /$ solder $^{\mathrm{a}}$ & $0 \cdot 2516$ & $398 \cdot 0$ & $78 \cdot 1$ & $118 \cdot 0$ & 121.468 & $2 \cdot 9$ \\
\hline 13 & $\mathrm{Cu} /$ solder $^{\mathrm{a}}$ & $0 \cdot 2894$ & $398 \cdot 0$ & $78 \cdot 1$ & $125 \cdot 0$ & $128 \cdot 821$ & $3 \cdot 0$ \\
\hline 14 & $\mathrm{Cu} /$ solder $^{\mathrm{a}}$ & $0 \cdot 291$ & $398 \cdot 0$ & $78 \cdot 1$ & $125 \cdot 0$ & $129 \cdot 143$ & $3 \cdot 3$ \\
\hline 15 & Cellosize/flexol ${ }^{\mathrm{b}}$ & $0 \cdot 30$ & 0.616 & $0 \cdot 161$ & 0.235 & $0 \cdot 257$ & $9 \cdot 7$ \\
\hline 16 & Water/oil solvent ${ }^{\mathrm{c}}$ & $0 \cdot 20$ & $0 \cdot 604$ & $0 \cdot 182$ & $0 \cdot 266$ & $0 \cdot 247$ & $6 \cdot 9$ \\
\hline 17 & Cellosize/polypropylene glycol $^{\mathrm{c}}$ & $0 \cdot 30$ & $0 \cdot 55$ & $0 \cdot 150$ & 0.234 & $0 \cdot 238$ & 1.9 \\
\hline 18 & Water/mineral oil ${ }^{\mathrm{c}}$ & $0 \cdot 40$ & $0 \cdot 611$ & $0 \cdot 149$ & $0 \cdot 292$ & $0 \cdot 281$ & $3 \cdot 7$ \\
\hline 19 & Selenium/polypropylene glycol $^{\mathrm{d}}$ & $0 \cdot 40$ & $5 \cdot 192$ & $0 \cdot 14$ & $0 \cdot 422$ & $0 \cdot 363$ & $13 \cdot 9$ \\
\hline 20 & Ti. Oxide/methylvinyl ${ }^{\mathrm{e}}$ & $0 \cdot 25$ & $7 \cdot 985$ & $0 \cdot 174$ & $0 \cdot 461$ & $0 \cdot 337$ & $26 \cdot 7$ \\
\hline 21 & Graphite/water ${ }^{f^{\prime}}$ & $0 \cdot 05$ & $160 \cdot 5$ & 0.666 & 0.832 & $0 \cdot 862$ & $3 \cdot 6$ \\
\hline 22 & Graphite/water ${ }^{\mathrm{f}}$ & $0 \cdot 11$ & $160 \cdot 5$ & 0.666 & $1 \cdot 132$ & $1 \cdot 004$ & $11 \cdot 2$ \\
\hline 23 & Graphite/water $^{\mathrm{f}}$ & $0 \cdot 17$ & $160 \cdot 5$ & 0.666 & 1.439 & $0 \cdot 145$ & $20 \cdot 4$ \\
\hline 24 & Selenium/polypropylene glycol $^{\mathrm{d}}$ & $0 \cdot 10$ & $5 \cdot 208$ & $0 \cdot 14$ & $0 \cdot 18$ & $0 \cdot 197$ & 9.7 \\
\hline 25 & Selenium/polypropylene glycol $^{\mathrm{d}}$ & $0 \cdot 30$ & $5 \cdot 208$ & $0 \cdot 14$ & $0 \cdot 316$ & $0 \cdot 296$ & $6 \cdot 2$ \\
\hline 26 & Selenium/polypropylene glycol $^{\mathrm{d}}$ & $0 \cdot 40$ & $5 \cdot 208$ & $0 \cdot 14$ & 0.423 & $0 \cdot 363$ & $14 \cdot 1$ \\
\hline 27 & Water/oil solvent $\mathrm{c}^{\mathrm{c}}$ & $0 \cdot 20$ & $0 \cdot 605$ & $0 \cdot 182$ & $0 \cdot 267$ & $0 \cdot 247$ & $7 \cdot 2$ \\
\hline 28 & Water/oil solvent ${ }^{\mathrm{c}}$ & $0 \cdot 40$ & 0.607 & $0 \cdot 173$ & $0 \cdot 312$ & $0 \cdot 316$ & $1 \cdot 3$ \\
\hline 29 & Water/mineral oil ${ }^{\mathrm{c}}$ & $0 \cdot 20$ & 0.611 & $0 \cdot 149$ & $0 \cdot 234$ & $0 \cdot 208$ & $11 \cdot 0$ \\
\hline 30 & Water/mineral oil ${ }^{\mathrm{c}}$ & $0 \cdot 40$ & $0 \cdot 611$ & $0 \cdot 149$ & $0 \cdot 293$ & $0 \cdot 281$ & $4 \cdot 1$ \\
\hline 31 & Cellosize/F plasticizer ${ }^{\mathrm{b}}$ & $0 \cdot 10$ & $0 \cdot 551$ & $0 \cdot 166$ & $0 \cdot 190$ & $0 \cdot 196$ & $3 \cdot 2$ \\
\hline 32 & Cellosize/F plasticizer ${ }^{\mathrm{b}}$ & $0 \cdot 10$ & $0 \cdot 577$ & $0 \cdot 190$ & $0 \cdot 21$ & $0 \cdot 222$ & $6 \cdot 1$ \\
\hline 33 & Cellosize/F plasticizer ${ }^{\mathrm{b}}$ & $0 \cdot 30$ & 0.467 & $0 \cdot 135$ & $0 \cdot 18$ & $0 \cdot 212$ & $18 \cdot 1$ \\
\hline 34 & Cellosize/F plasticizer ${ }^{\mathrm{b}}$ & $0 \cdot 30$ & $0 \cdot 551$ & $0 \cdot 166$ & $0 \cdot 236$ & $0 \cdot 259$ & $10 \cdot 1$ \\
\hline 35 & Cellosize/F plasticizer ${ }^{b}$ & $0 \cdot 30$ & $0 \cdot 577$ & $0 \cdot 190$ & $0 \cdot 256$ & $0 \cdot 292$ & $14 \cdot 4$ \\
\hline 36 & Cellosize/polypropylene glycol $^{\mathrm{b}}$ & $0 \cdot 10$ & $0 \cdot 551$ & $0 \cdot 150$ & $0 \cdot 182$ & $0 \cdot 178$ & $1 \cdot 8$ \\
\hline 37 & Cellosize/polypropylene glycol $^{\mathrm{b}}$ & $0 \cdot 10$ & $0 \cdot 577$ & $0 \cdot 154$ & $0 \cdot 180$ & $0 \cdot 183$ & $2 \cdot 0$ \\
\hline 38 & Cellosize/polypropylene glycol $^{\mathrm{b}}$ & $0 \cdot 30$ & 0.467 & $0 \cdot 110$ & $0 \cdot 157$ & $0 \cdot 179$ & $14 \cdot 1$ \\
\hline 39 & Lead powder/Si rubber ${ }^{\mathrm{g}}$ & 0.05 & $34 \cdot 72$ & $0 \cdot 385$ & $0 \cdot 463$ & $0 \cdot 492$ & $6 \cdot 2$ \\
\hline 40 & Lead powder/Si rubber ${ }^{\mathrm{g}}$ & $0 \cdot 16$ & $34 \cdot 72$ & $0 \cdot 385$ & $0 \cdot 651$ & $0 \cdot 637$ & $2 \cdot 0$ \\
\hline 41 & Lead powder/Si rubber ${ }^{\mathrm{g}}$ & $0 \cdot 24$ & $34 \cdot 72$ & $0 \cdot 385$ & $0 \cdot 862$ & $0 \cdot 751$ & $12 \cdot 8$ \\
\hline 42 & Bi powder/Si rubber ${ }^{\mathrm{g}}$ & 0.05 & $8 \cdot 33$ & $0 \cdot 385$ & 0.433 & $0 \cdot 468$ & $8 \cdot 2$ \\
\hline 43 & Bi powder/Si rubber ${ }^{g}$ & $0 \cdot 16$ & $8 \cdot 33$ & $0 \cdot 385$ & $0 \cdot 591$ & $0 \cdot 596$ & $1 \cdot 0$ \\
\hline 44 & $\mathrm{Bi}$ powder/Si rubber ${ }^{\mathrm{g}}$ & $0 \cdot 24$ & $8 \cdot 33$ & $0 \cdot 385$ & 0.734 & 0.696 & $5 \cdot 1$ \\
\hline 45 & $\mathrm{ZnO} /$ methyl vinyl $^{\mathrm{e}}$ & $0 \cdot 15$ & $23 \cdot 1$ & $0 \cdot 1743$ & $0 \cdot 378$ & $0 \cdot 284$ & $24 \cdot 6$ \\
\hline 46 & $\mathrm{TiO} /$ methyl vinyl $^{\mathrm{e}}$ & $0 \cdot 25$ & $7 \cdot 81$ & $0 \cdot 174$ & $0 \cdot 462$ & $0 \cdot 337$ & $27 \cdot 0$ \\
\hline 47 & Silica powder/dimethyl vinyl ${ }^{\mathrm{e}}$ & $0 \cdot 10$ & 1.68 & $0 \cdot 176$ & $0 \cdot 231$ & $0 \cdot 227$ & $1 \cdot 7$ \\
\hline 48 & Silica powder/dimethyl vinyl ${ }^{\mathrm{e}}$ & $0 \cdot 15$ & 1.68 & $0 \cdot 174$ & $0 \cdot 252$ & $0 \cdot 246$ & $2 \cdot 09$ \\
\hline 49 & Silica powder/dimethyl vinyl ${ }^{\mathrm{e}}$ & $0 \cdot 25$ & $1 \cdot 68$ & $0 \cdot 174$ & $0 \cdot 29$ & $0 \cdot 294$ & $1 \cdot 4$ \\
\hline 50 & $\mathrm{ZnO} /$ synthetic rubber $^{\mathrm{e}}$ & $0 \cdot 21$ & $23 \cdot 1$ & $0 \cdot 168$ & 0.430 & $0 \cdot 311$ & $27 \cdot 5$ \\
\hline 51 & $\mathrm{TiO} /$ synthetic rubber $^{\mathrm{e}}$ & $0 \cdot 18$ & $7 \cdot 81$ & $0 \cdot 168$ & $0 \cdot 359$ & $0 \cdot 283$ & $21 \cdot 0$ \\
\hline \multicolumn{7}{|c|}{ Average deviation } & $7 \cdot 8 \%$ \\
\hline
\end{tabular}

${ }^{a}$ Lee and Taylor (1976); ${ }^{b}$ Nahas and Couper (1966); ${ }^{c}$ Knudsen and Wand (1958); ${ }^{\mathrm{d}}$ Baxley and Couper (1966); ${ }^{\mathrm{e}}$ Ratcliffe (1962); ${ }^{\mathrm{f}}$ Sugawara and Hamada (1970) and ${ }^{\mathrm{g}}$ Cheng and Vachon (1969). 
best fits the curve obtained in figures 2-4 where $C_{1}$ and $C_{2}$ are constants. These constants are different for different type of materials. The values of these constants for solid-air, emulsion, suspension, granular and solid-solid two-phase systems are 0.7282 and 0.0062 , for Al-air system constants are 0.034 and 0.7111 , for Al-water system constants are 0.5217 and $0 \cdot 1535$, for reticulated vitreous carbon (RVC)-air system constants are 0.491 and 0.5216 and for reticulated vitreous carbon (RVC)-water system constants are 0.6246 and 0.0604 , respectively.

On putting (21) as the porosity correction term in (19) we have calculated values of ETC for a large number of samples reported in the literature. Tables 1-2 show a comparison of experimental results of ETC and calculated values from (19). The average deviation is $7.8 \%$ for solid-air, emulsion, suspension, granular and solid-solid two-phase systems shown in table 1 and for metal and nonmetal foams the average deviation is $6.2 \%$ shown in table 2 , respectively. The constants $C_{1}$ and $C_{2}$ in (21) are different for metal

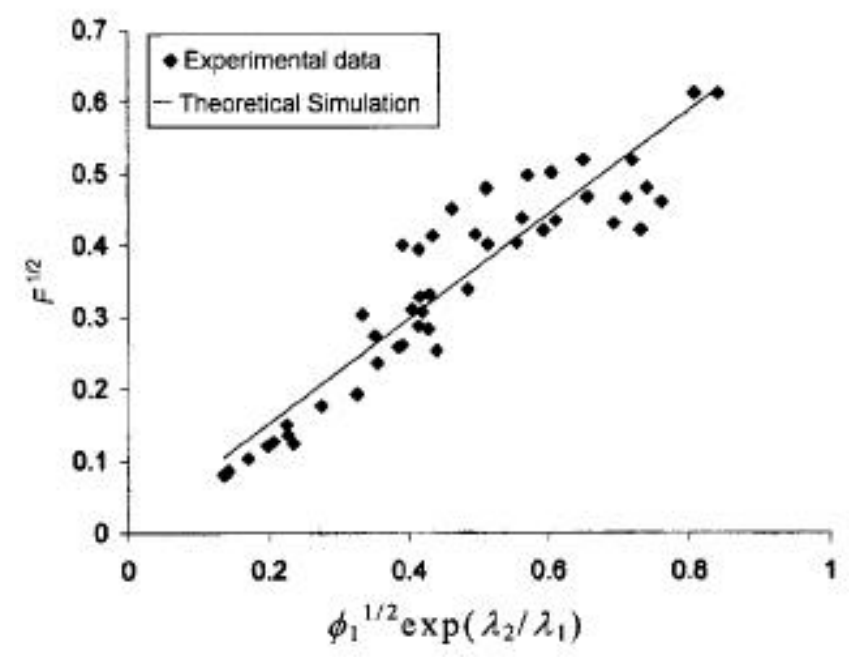

Figure 2. The variation of porosity correction term $F^{1 / 2}$ vs $\phi_{1}{ }^{1 / 2}$ $\exp \left(\lambda_{2} / \lambda_{1}\right)$.

Table 2. Comparison of ETC values for two-phase systems using ellipsoidal particles (19). The thermal conductivity is in $\mathrm{W} \mathrm{m}^{-1} \mathrm{~K}^{1}$.

\begin{tabular}{|c|c|c|c|c|c|c|c|}
\hline $\begin{array}{l}\text { Sl. } \\
\text { No. }\end{array}$ & Type of the sample & $\phi_{1}$ & $\lambda_{1}$ & $\lambda_{2}$ & $\lambda \mathrm{e}(\operatorname{expt})$ & $\begin{array}{c}\lambda e(\text { theo.) } \\
\text { by (19) }\end{array}$ & $\begin{array}{c}\% \\
\text { Error }\end{array}$ \\
\hline 1 & $\mathrm{Al} /$ air $^{\mathrm{h}}$ & 0.029 & $218 \cdot 0$ & $0 \cdot 026$ & $2 \cdot 7$ & $2 \cdot 720$ & $0 \cdot 7$ \\
\hline 2 & $\mathrm{Al} / \mathrm{air}^{\mathrm{h}}$ & $0 \cdot 054$ & $218 \cdot 0$ & $0 \cdot 026$ & $4 \cdot 6$ & $3 \cdot 916$ & $14 \cdot 8$ \\
\hline 3 & $\mathrm{Al} / \mathrm{air}^{\mathrm{h}}$ & 0.095 & $218 \cdot 0$ & 0.026 & $6 \cdot 7$ & $8 \cdot 454$ & $26 \cdot 2$ \\
\hline 4 & $\mathrm{Al} / \mathrm{air}^{\mathrm{h}}$ & $0 \cdot 051$ & $218 \cdot 0$ & 0.026 & $3 \cdot 9$ & $3 \cdot 742$ & $4 \cdot 0$ \\
\hline 5 & $\mathrm{Al} / \mathrm{air}^{\mathrm{h}}$ & 0.091 & $218 \cdot 0$ & 0.026 & $6 \cdot 7$ & $7 \cdot 684$ & $14 \cdot 7$ \\
\hline 6 & $\mathrm{Al} / \mathrm{air}^{\mathrm{h}}$ & 0.022 & $218 \cdot 0$ & 0.026 & $2 \cdot 2$ & 2.455 & $11 \cdot 6$ \\
\hline 7 & $\mathrm{Al} / \mathrm{air}^{\mathrm{h}}$ & $0 \cdot 051$ & $218 \cdot 0$ & $0 \cdot 026$ & $4 \cdot 0$ & $3 \cdot 742$ & $6 \cdot 4$ \\
\hline 8 & $\mathrm{Al} / \mathrm{air}^{\mathrm{h}}$ & $0 \cdot 094$ & $218 \cdot 0$ & $0 \cdot 026$ & $6 \cdot 9$ & $8 \cdot 249$ & $19 \cdot 5$ \\
\hline 9 & $\mathrm{Al} / \mathrm{air}^{\mathrm{h}}$ & $0 \cdot 028$ & $218 \cdot 0$ & $0 \cdot 026$ & $2 \cdot 5$ & $2 \cdot 681$ & $7 \cdot 2$ \\
\hline 10 & $\mathrm{Al} / \mathrm{air}^{\mathrm{h}}$ & 0.048 & $218 \cdot 0$ & 0.026 & $3 \cdot 9$ & $3 \cdot 579$ & $8 \cdot 2$ \\
\hline 11 & $\mathrm{Al} /$ air $^{\mathrm{h}}$ & $0 \cdot 063$ & $218 \cdot 0$ & $0 \cdot 026$ & $4 \cdot 5$ & $4 \cdot 511$ & $0 \cdot 2$ \\
\hline 12 & $\mathrm{Al} /$ water $^{\mathrm{h}}$ & $0 \cdot 029$ & $218 \cdot 0$ & 0.615 & $3 \cdot 7$ & $3 \cdot 562$ & $3 \cdot 7$ \\
\hline 13 & $\mathrm{Al} /$ water $^{\mathrm{h}}$ & $0 \cdot 054$ & $218 \cdot 0$ & $0 \cdot 615$ & $5 \cdot 4$ & $4 \cdot 813$ & $10 \cdot 8$ \\
\hline 14 & $\mathrm{Al} /$ water $^{\mathrm{h}}$ & 0.095 & $218 \cdot 0$ & $0 \cdot 615$ & $7 \cdot 65$ & $8 \cdot 432$ & $10 \cdot 2$ \\
\hline 15 & $\mathrm{Al} /$ water $^{\mathrm{h}}$ & 0.051 & $218 \cdot 0$ & 0.615 & $4 \cdot 8$ & $4 \cdot 641$ & $3 \cdot 3$ \\
\hline 16 & $\mathrm{Al} /$ water $^{\mathrm{h}}$ & 0.091 & $218 \cdot 0$ & 0.615 & $7 \cdot 6$ & $7 \cdot 917$ & $4 \cdot 1$ \\
\hline 17 & $\mathrm{Al} /$ water $^{\mathrm{h}}$ & 0.022 & $218 \cdot 0$ & $0 \cdot 615$ & 3.05 & $3 \cdot 262$ & $6 \cdot 9$ \\
\hline 18 & $\mathrm{Al} /$ water $^{\mathrm{h}}$ & 0.051 & $218 \cdot 0$ & 0.615 & 4.95 & $4 \cdot 641$ & $6 \cdot 2$ \\
\hline 19 & $\mathrm{Al} /$ water $^{\mathrm{h}}$ & 0.094 & $218 \cdot 0$ & 0.615 & $7 \cdot 65$ & $8 \cdot 298$ & $8 \cdot 5$ \\
\hline 20 & $\mathrm{Al} /$ water $^{\mathrm{h}}$ & 0.028 & $218 \cdot 0$ & 0.615 & $3 \cdot 3$ & $3 \cdot 518$ & $6 \cdot 6$ \\
\hline 21 & $\mathrm{Al} /$ water $^{\mathrm{h}}$ & $0 \cdot 048$ & $218 \cdot 0$ & 0.615 & $4 \cdot 75$ & $4 \cdot 477$ & $5 \cdot 7$ \\
\hline 22 & $\mathrm{Al} /$ water $^{\mathrm{h}}$ & 0.063 & $218 \cdot 0$ & 0.615 & $5 \cdot 35$ & $5 \cdot 381$ & $0 \cdot 5$ \\
\hline 23 & RVC/air ${ }^{\text {h }}$ & 0.0336 & $8 \cdot 5$ & $0 \cdot 026$ & $0 \cdot 164$ & $0 \cdot 162$ & $1 \cdot 1$ \\
\hline 24 & RVC/air ${ }^{\text {h }}$ & 0.0276 & $8 \cdot 5$ & $0 \cdot 026$ & $0 \cdot 15$ & $0 \cdot 151$ & $0 \cdot 8$ \\
\hline 25 & $\mathrm{RVC}_{\text {air }}{ }^{\mathrm{h}}$ & 0.0385 & $8 \cdot 5$ & $0 \cdot 026$ & $0 \cdot 17$ & $0 \cdot 171$ & $0 \cdot 9$ \\
\hline 26 & $\mathrm{RVC}$ air ${ }^{\mathrm{h}}$ & 0.0319 & $8 \cdot 5$ & $0 \cdot 026$ & $0 \cdot 16$ & $0 \cdot 159$ & $0 \cdot 6$ \\
\hline 27 & RVC/water ${ }^{\mathrm{h}}$ & 0.0336 & $8 \cdot 5$ & $0 \cdot 615$ & 0.73 & 0.731 & $0 \cdot 3$ \\
\hline 28 & RVC/water ${ }^{\mathrm{h}}$ & 0.0276 & $8 \cdot 5$ & $0 \cdot 615$ & 0.722 & 0.720 & $0 \cdot 2$ \\
\hline 29 & $\mathrm{RVC}$ water ${ }^{\mathrm{h}}$ & 0.0385 & $8 \cdot 5$ & $0 \cdot 615$ & 0.743 & $0 \cdot 741$ & $0 \cdot 3$ \\
\hline 30 & RVC/water ${ }^{\mathrm{h}}$ & $0 \cdot 0319$ & $8 \cdot 5$ & 0.615 & 0.727 & 0.728 & $0 \cdot 2$ \\
\hline \multicolumn{7}{|c|}{ Average deviation } & $6 \cdot 2 \%$ \\
\hline
\end{tabular}

${ }^{\mathrm{h}}$ Bhattacharya et al (2002). 


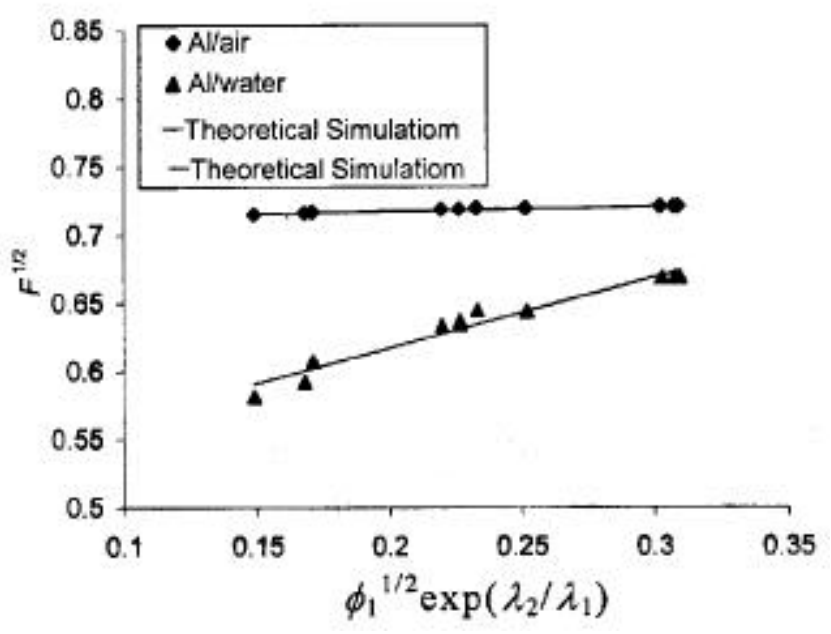

Figure 3. The variation of porosity correction term $F^{1 / 2}$ vs $\phi_{1}{ }^{1 / 2}$ $\exp \left(\lambda_{2} / \lambda_{1}\right)$.

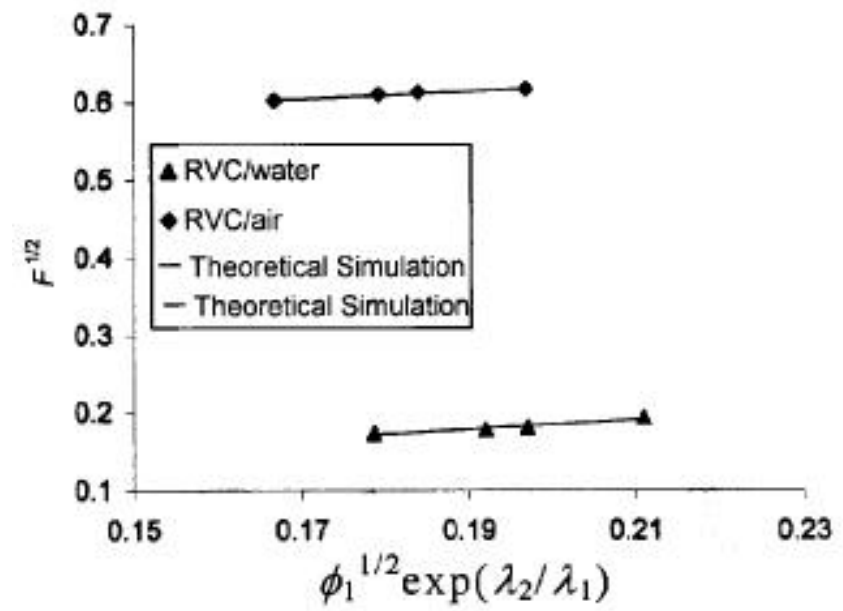

Figure 4. The variation of porosity correction term $F^{1 / 2}$ vs $\phi_{1}{ }^{1 / 2}$ $\exp \left(\lambda_{2} / \lambda_{1}\right)$.

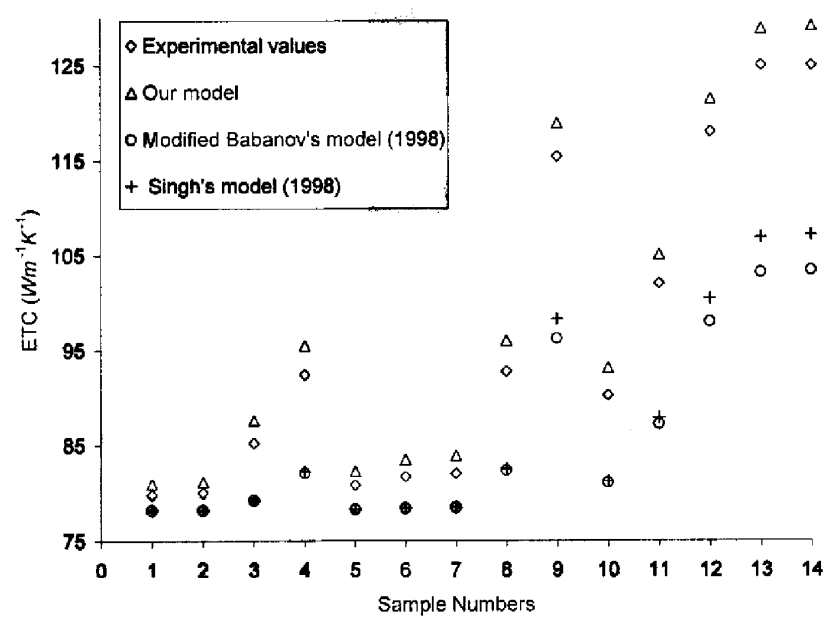

Figure 5. Comparison between experimental and theoretical values of ETC of the samples (sample nos 1-14, table 1). foams. The reason is that a metal has very large thermal conductivity in the solid form, but even then, metal foams have exceptionally low ETC. In the solid form, other atoms of the metal bound each atom of the metal by a strong bond called metallic bond, which is responsible for the stiffness, hardness and high value of thermal conductivities for the metals. As we turn the metal to metal foam, the metallic bond no more exists in between the grains of the metal. Therefore, at the boundary of the grain a thin layer of insulating air is formed which reduces the metal to metal contact, thus, the overall ETC of the whole system reduces. The average percentage deviation from the experimental results for modified Babanov's model (Singh et al 1998) and Singh's (1998) model has been calculated and shown in figures 5-6. For foam-like materials we have used Boomsma's (2001) model and Bhattacharya's (2002) model for comparison of $\lambda_{e}$ as shown in figures 7-10. We have observed from these figures that when the volume fraction of the solid phase increases, ETC increases. We

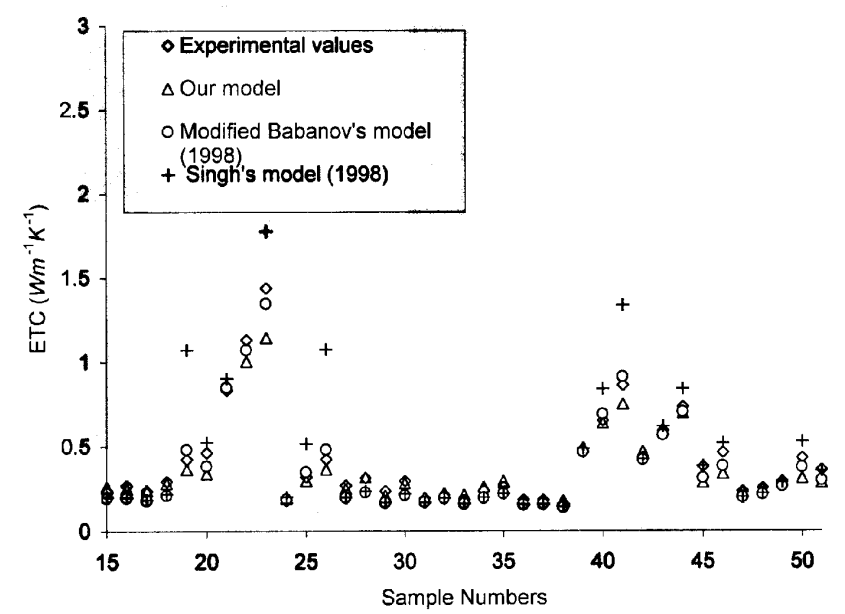

Figure 6. Comparison between experimental and theoretical values of ETC of the samples (sample nos 15-51, table 1).

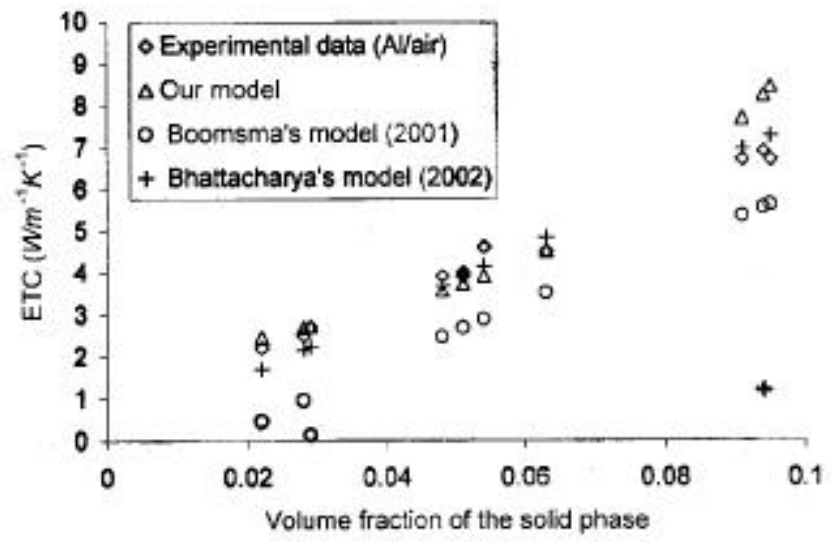

Figure 7. Comparison between experimental and theoretical values of ETC. 


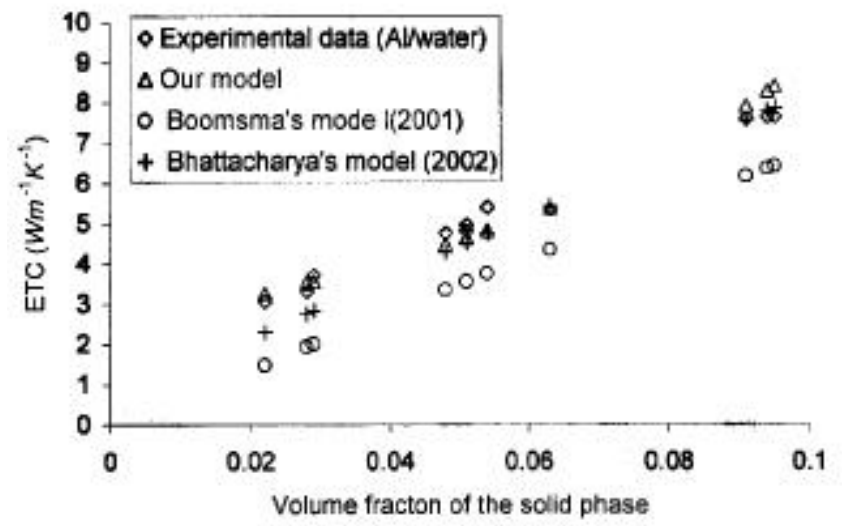

Figure 8. Comparison between experimental and theoretical values of ETC.

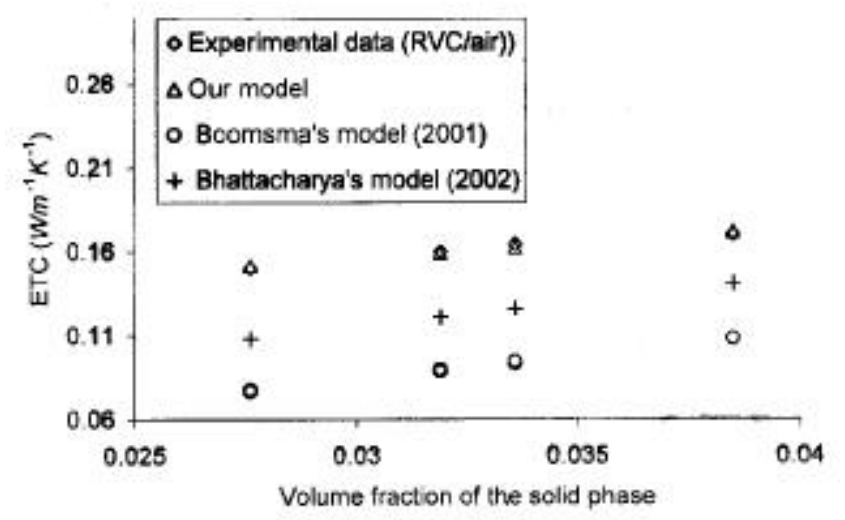

Figure 9. Comparison between experimental and theoretical values of ETC.

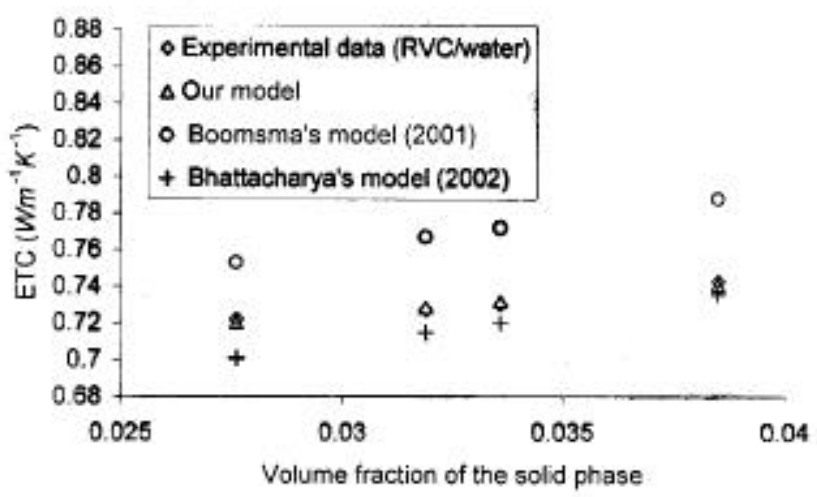

Figure 10. Comparison between experimental and theoretical values of ETC.

have also observed from figures 5-10 that for our model the average percentage deviation is better than other models.

\section{Conclusions}

(I) The model is capable of predicting ETCs close to the experimental values even for mixtures of higher conducti- vity ratios and high porosities, whereas one may find that other models give higher deviations in those situations.

(II) This model enables one to avoid the introduction of sphericity or any other factor in the expression of ETC, making the model simple but powerful enough without compromising on the results.

(III) The proposed model for prediction of the ETC of two-phase systems holds not only for systems for which the ETC of the constituent phases are comparable, but also for systems having a high ETC ratio of the solid and fluid phases.

(IV) This model generalizes the work of Singh et al (1998), who treated a three-dimensional cubic array with spherical particles. The generalization to ellipsoidal particles is a useful one, since the ellipsoid can be used to model a variety of particle shapes, including discs and fibres in limiting cases.

\section{Acknowledgements}

The authors would like to thank Prof. D R Chaudhary for critical comments and helpful discussion. (JR) is grateful to CSIR, New Delhi, for the award of a SRF.

\section{Appendix}

The modified Babanov's cubic particle model (Singh et al 1998) is

$$
\lambda_{\mathrm{e}}=\frac{\left[\lambda_{2}\left\{\lambda_{2}+F^{2 / 3}\left(\lambda_{1}-\lambda_{2}\right)\right\}\right]}{\left[\lambda_{2}+F^{2 / 3}\left(\lambda_{1}-\lambda_{2}\right)\left(1-F^{1 / 3}\right)\right]},
$$

where

$$
F=\left[1-\exp \left\{-(0.92) \phi_{1}^{2} \ln \left(\lambda_{1} / \lambda_{2}\right)\right\}\right] .
$$

Singh's (1998) spherical particle model is

$$
\lambda_{\mathrm{e}}=\frac{\left[\lambda_{2}\left\{\lambda_{2}+0 \cdot 8060 F^{2 / 3}\left(\lambda_{1}-\lambda_{2}\right)\right\}\right]}{\left[\lambda_{2}+F^{2 / 3}\left\{0 \cdot 8060\left(\lambda_{1}-\lambda_{2}\right)\left(1-1 \cdot 2407 F^{1 / 3}\right)\right\}\right]},
$$

where

$$
F=\left[1-\exp \left\{-(0.92) \phi_{1}^{2} \ln \left(\lambda_{1} / \lambda_{2}\right)\right\}\right] .
$$

The Boomsma's (2001) model is

$$
\lambda_{\mathrm{e}}=\frac{\sqrt{ } 2}{2\left[R_{\mathrm{A}}+R_{\mathrm{B}}+R_{\mathrm{C}}+R_{\mathrm{D}}\right.},
$$

where

$$
\begin{aligned}
R_{\mathrm{A}}= & 4 F /\left[\left\{2 e^{2}+\pi F(1-e)\right\} \lambda_{1}+\right. \\
& \left.\left\{4-2 e^{2}-\pi F(1-e)\right\} \lambda_{2}\right], \\
R_{\mathrm{B}}= & (e-2 F)^{2} /\left[(e-2 F) e^{2} \lambda_{1}+\right. \\
& \left.\left\{2 e-4 F-(e-2 F) e^{2}\right\} \lambda_{2}\right],
\end{aligned}
$$




$$
\begin{aligned}
R_{\mathrm{C}}= & (\sqrt{2}-2 e)^{2} /\left[\left\{2 \pi F^{2}(1-2 e \sqrt{ } 2) \lambda_{1}\right\}+\right. \\
& \left.2\left\{\sqrt{ } 2-2 e-\pi F^{2}(1-2 e \sqrt{ } 2)\right\} \lambda_{2}\right], \\
R_{\mathrm{D}}= & 2 e /\left[e^{2} \lambda_{1}+\left(4-e^{2}\right) \lambda_{2}\right], F=\sqrt{ }[\sqrt{ } 2\{2- \\
& \left.\left.(5 / 8) e^{3} \sqrt{ } 2-2\left(1-\phi_{1}\right)\right\} /\{\pi(3-4 e \sqrt{ } 2-e)\}\right],
\end{aligned}
$$

and

$$
e=0 \cdot 339 \text {. }
$$

Bhattacharya's (2002) model is

$$
\lambda_{\mathrm{e}}=F\left\{\phi_{1} \lambda_{1}+\left(1-\phi_{1}\right) \lambda_{2}\right\}+\frac{(1-F)}{\left\{\phi_{1} / \lambda_{1}+\left(1-\phi_{1}\right) \lambda_{2}\right\}},
$$

where

$$
F=0 \cdot 35 .
$$

Symbols involved in the formulae (22)-(25) have the same meaning as in the previous part in the paper.

\section{References}

Antohe B V, Lage J L, Price D C and Weber R M 1996 Int. J. Heat Fluid Flow 17594

Babanov A A 1957 Sov. Phys. Tech. Phys. 2476

Baxley A L and Couper J R 1966 Thermal conductivity of twophase systems Part IV (Thermal conductivity of suspensions): Research report series No. 8, University of Arkansas

Bhattacharya A, Calmidi V V and Mahajan R L 2002 Int. J. Heat \& Mass Transfer 451017

Boomsma K and Poulikakos D 2001 Int. J. Heat \& Mass Transfer 44827

Brailsford A D and Major K G 1964 Br. J. Appl. Phys. 15313

Calmidi V V and Mahajan R L 1999 ASME J. Heat Transfer 121466

Cheng S C and Vachon R I 1969 Int. J. Heat \& Mass Transfer 12249
Hadley G R 1986 Int. J. Heat \& Mass Transfer 20909

Hsu C T, Cheng P and Wong K W 1994 Int. J. Heat \& Mass Transfer 372751

Hunt M L and Tien C L 1988 Int. J. Heat \& Mass Transfer 31 301

Kampf H and Karsten G 1970 Nucl. Appl. Technol. 9208

Kaviany M 1995 Principles of heat transfer in porous media (New York: Springer) p. 119

Knudsen J G and Wand R H 1958 Ind. Eng. Chem. 50166727

Koh J C Y and Fortini G 1973 Int. J. Heat \& Mass Transfer 16 2013

Lee H J and Taylor R E 1976 J. Appl. Phys. 47148

Misra K, Shrotriya A K, Singh R and Chaudhary D R 1994 J. Phys. D: Appl. Phys. 27732

Nahas N C and Couper J R 1966 Thermal conductivity of twophase systems Part II, Research Report series, University of Arkansas

Oshima N and Watari N 1989 Jap. Soc. Mech. Eng. Int. J. 32 225

Pande R N, Kumar V and Chaudhary D R 1984 Pramana-J. Phys. 2263

Peddicord K L 1976 Trans. Am. Nucl. Soc. 241976

Poulikakos D P and Renken K J 1987 Int. J. Heat Mass Transfer 109880

Ratcliffe E H 1962 Trans. Inst. Rubber Ind. 38181

Singh K J, Singh Ramvir and Chaudhary D R 1998 J. Phys. D: Appl. Phys. 311681

Singh Ramvir, Singh K J and Chaudhary D R 1995 J. Phys. D: Appl. Phys. 281573

Sugawara A and Hamada A 1970 10th Thermal conductivity conference (Massachusetts, USA) III p. 7

Tareev B 1975 Physics of dielectric materials (Moscow: Mir) p. 128

Tien C L and Vafai K 1979 Prog. Astronaut. 65135

Verma L S, Shrotriya A K, Singh R and Chaudhary D R 1991 J. Phys. D: Appl. Phys. 241729

Zehner P and Schlünder E U 1970 Chem. Ing. Tech. 42933 